\title{
MULTIPLE SYSTEMIC METASTASES OF POSTERIOR FOSSA - PRIMITIVE NEUROECTODERMAL TUMOR (PF-PNET) IN ADULT
}

\section{Case report}

\author{
João Paulo Mattos', Leonardo Bonilha², Daniele Ferreira ${ }^{3}$, Wilson Borges', \\ Yvens Barbosa Fernandes, Guilherme Borges ${ }^{5}$
}

\begin{abstract}
We present the case of a 30-year female patient with multiple systemic metastases of posterior fossa primitive neuroectodermal tumor (PF- PNET) and present a review concerning the usual presentation, sign and symptoms, radiological aspects, pathways of spread, genetic patterns and treatment of PF-PNET. The biological behavior of PF - PNET is analyzed taking into consideration the presence of systemic metastases.
\end{abstract}

KEY WORDS: medulloblastoma, metastases, primitive neuroectodermal tumor (PNET).

\begin{abstract}
Metastases sistêmicas múltiplas de tumor neuroectodérmico primitivo (PNET) na fossa posterior em adulto: relato de caso

RESUMO - A presença de metástases múltiplas sistêmicas decorrentes de um tumor neuroectodérmico primitivo (PNET) numa paciente de 30 anos é relatada. É feita pelos autores revisão desta patologia, incluindo sua apresentação clínica, sinais e sintomas, aspectos radiológicos, vias de disseminação, aspectos genéticos e tratamento. É abordado na discussão do caso particularmente o comportamento metastático dos meduloblastomas, comparativamente com os não metastatizantes.
\end{abstract}

PALAVRAS-CHAVE: meduloblastoma, metástase, tumor neuroectodérmico primitivo (PNET).

The term medulloblastoma was coined by Bailey and Cushing in $1925^{1}$ after the observation of malignant midline tumors of posterior fossa with unique features. Hart and Earle in $1973^{2}$ used the term primitive neuroectodermal tumor ( PNET) during the description of supratentorial tumors with small, round and blue cells. Rorke in $1983^{3}$ described that these cells observed in supratentorial tumors were undistinguishable from those observed in medulloblastomas. The World Health Organization, after that, formally introduced the term posterior fossa primitive neuroectodermal tumor (PF-PNET) for Medulloblastomas. In 1936, Nelson ${ }^{4}$ reported the first case of metastases of medulloblastoma outside the Central Nervous System (CNS). Thereafter, some reports of spread outside of the CNS of PF - PNET have been published, and most of them in pediatric population. PF-PNET represents about 15 to $30 \%$ of childhood brain tumors ${ }^{5-8}$. The frequency in the adult population ranges from $1 \%$ to $2 \%$ among CNS tumors ${ }^{6-8}$. Metastases outside the CNS are rare. The overall incidence of non-CNS involvement by PF PNET comprises approximately $7 \%$.

We present a case of multiple systemic metastases of a PF - PNET in a female adult patient, and a literature review.

\section{CASE}

A 30-year female patient presented as an outpatient to the University Hospital complaining of generalized bone pain. Her physical examination upon arrival was unremarkable and laboratory evaluation showed mild anemia, elevation of sedimentation rate and hypercalcemia. She had a medical history of resection of a medulloblastoma performed four years before. One year after the first surgical approach, local recurrence occurred and another gross to-

Disciplina de Neurocirurgia. Faculdade de Ciências Médicas da Universidade de Campinas (UNICAMP): ${ }^{1}$ Médico Residente; ${ }^{2}$ Médico PósGraduando; ${ }^{3}$ Médica Residente; ${ }^{4}$ Médico Contratado, ${ }^{5}$ Professor Doutor.

Received 3 June 2002, received in final form 29 August 2002. Accepted 12 September 2002. 


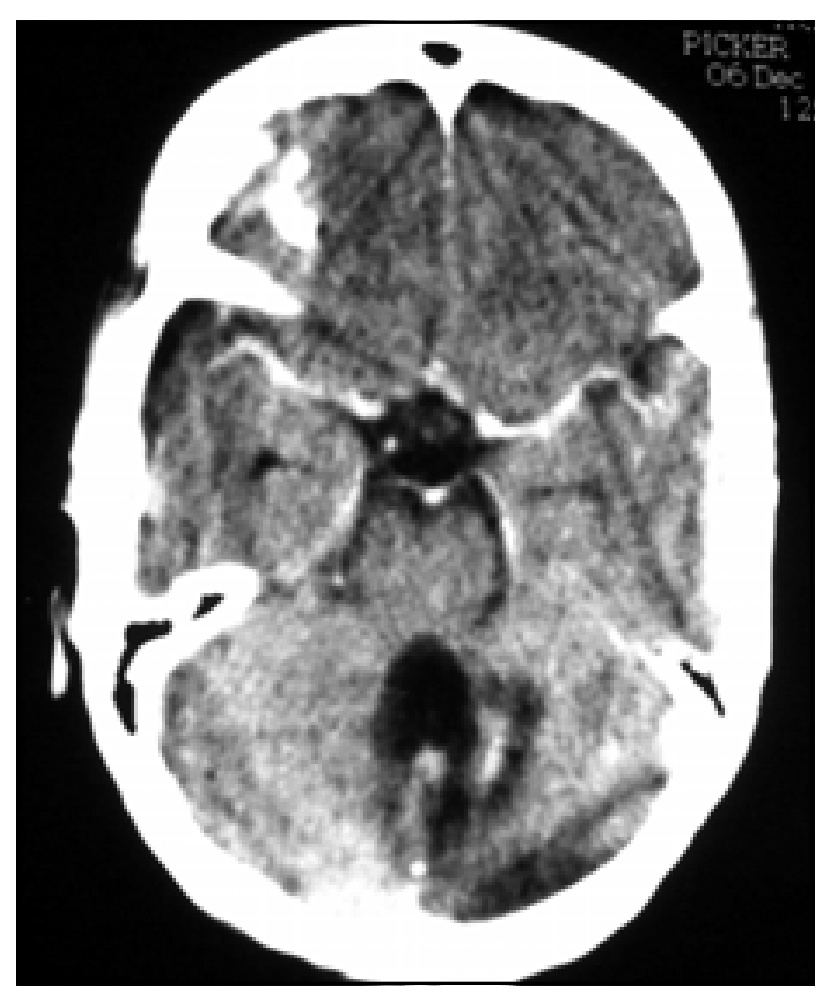

Fig 1. Absence of intracranial recurrence of the medulloblastoma in a postoperative axial CT scan with contrast enhancement.

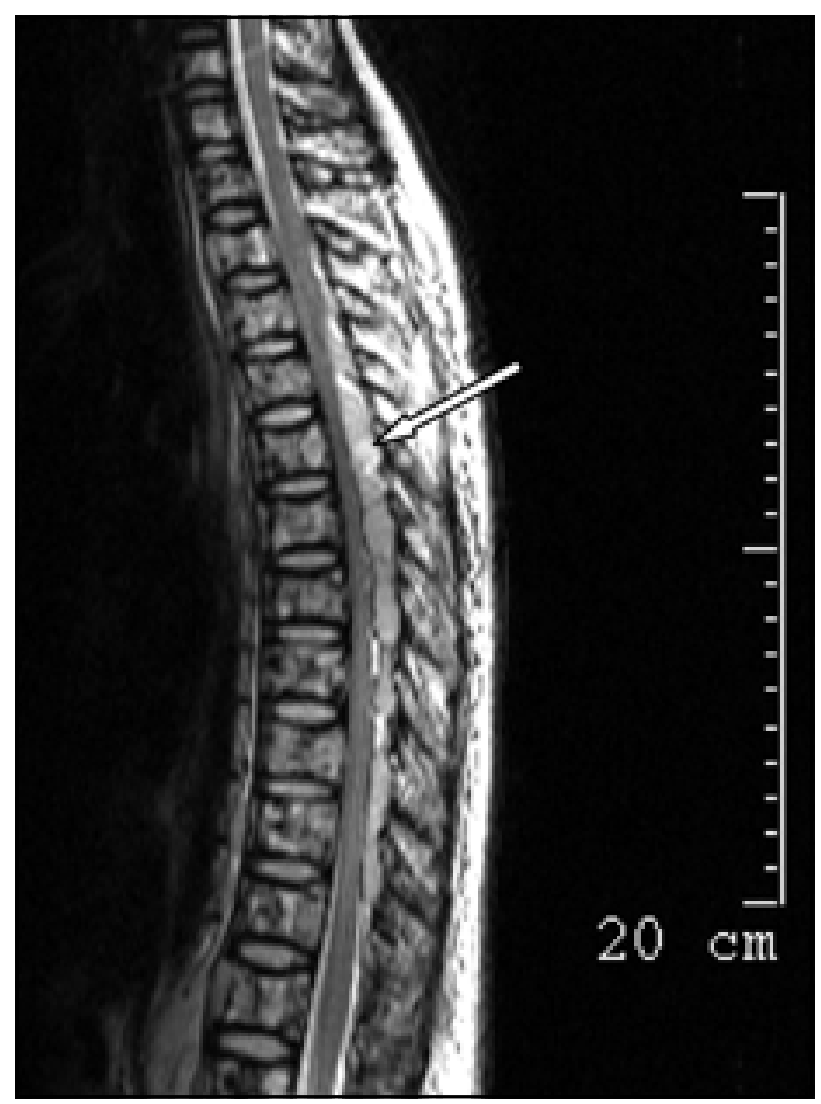

Fig 2. Sagittal T2-weighted MRI of the spinal cord showing an extensive intra-axial metastasis. $(A=$ anterior). tal resection of the cerebellar tumor was done, followed by posterior fossa radiotherapy performed with $56 \mathrm{~Gy}$ and craniospinal axis radiotherapy with $36 \mathrm{~Gy}$.

She continued to be followed in the outpatient clinic and two months later she presented at emergency room with poor general status, dyspnea, lumbar pain and progressive paraparesis with sphincter disturbance, and pyramidal signs in both lower extremities. Her clinical examination also revealed a hard nodule at eleventh left rib. It was not possible to define then a spinal cord level of sensitive deficit. X- Ray evaluation showed extensive bilateral pleural effusion and blastic lesions at ribs and vertebral bodies. The suspicion of bone metastases was enhanced by osseous radionuclide study. Thoracentesis fluid analysis was positive for malignant cells. Brain imaging did not show local posterior fossa or supratentorial recurrence (Fig 1). The spinal cord Magnetic Resonance (MR) study showed multiple lesions compressing the spinal cord from T3 to $\mathrm{T} 11$, lesions at paravertebral musculature, pleural and lung nodules (Figs 2 and 3 ). She was submitted to additional spinal axis radiation therapy $(0,8 \mathrm{~Gy})$ but a complete sensitive, motor and sphincter deficit developed in spite of the treatment. A bone excision biopsy was performed confirming undifferentiated small malignant cells with tumor markers compatible with medulloblastoma ( Sinaptofisin +, GFAP +, Vimentin +, S100 -, LCA -, AE1AE3 -, Neurophilaments - ). Due to her bad clinical status, chemotherapeutic regimen was not performed and the patient died two months later.

\section{DISCUSSION}

PF - PNET is a rare tumor in adult patients and systemic metastases are even rarer. The PF - PNET has a male preponderance $2: 16,10$ and the average age of presentation is between $24-34$ years when the tumor occurs in adults ${ }^{6,8,9}$. Headache is the most common symptom, followed by ataxia ${ }^{6}$. Papiledema, nauseas, vomiting, cranial nerve palsies, blurred vision and mental changes are also found. When extra cranial metastases are present, hypercalcemia, thoracic or abdominal pain, dyspnea and bone nodule are the most prominent features.

Bone is a frequent site for PF - PNET systemic metastases $^{11-13}$ and blastic lesions are the most frequent radiological pattern ${ }^{14}$. Lymph nodes, lungs, abdominal cavity, breast and pancreas are also sites of PF PNET spread outside the CNS ${ }^{15,16}$. Different pathways of spread of PF - PNET cells have been postulated since different organs have been described as harboring metastases. The possible routes for dissemination are lymphatic vessels, cerebrospinal fluid in the sites where nerve fibers leave the CNS, and blood, through arachnoid villi and the increased blood brain permeability ${ }^{9,10,17}$. 


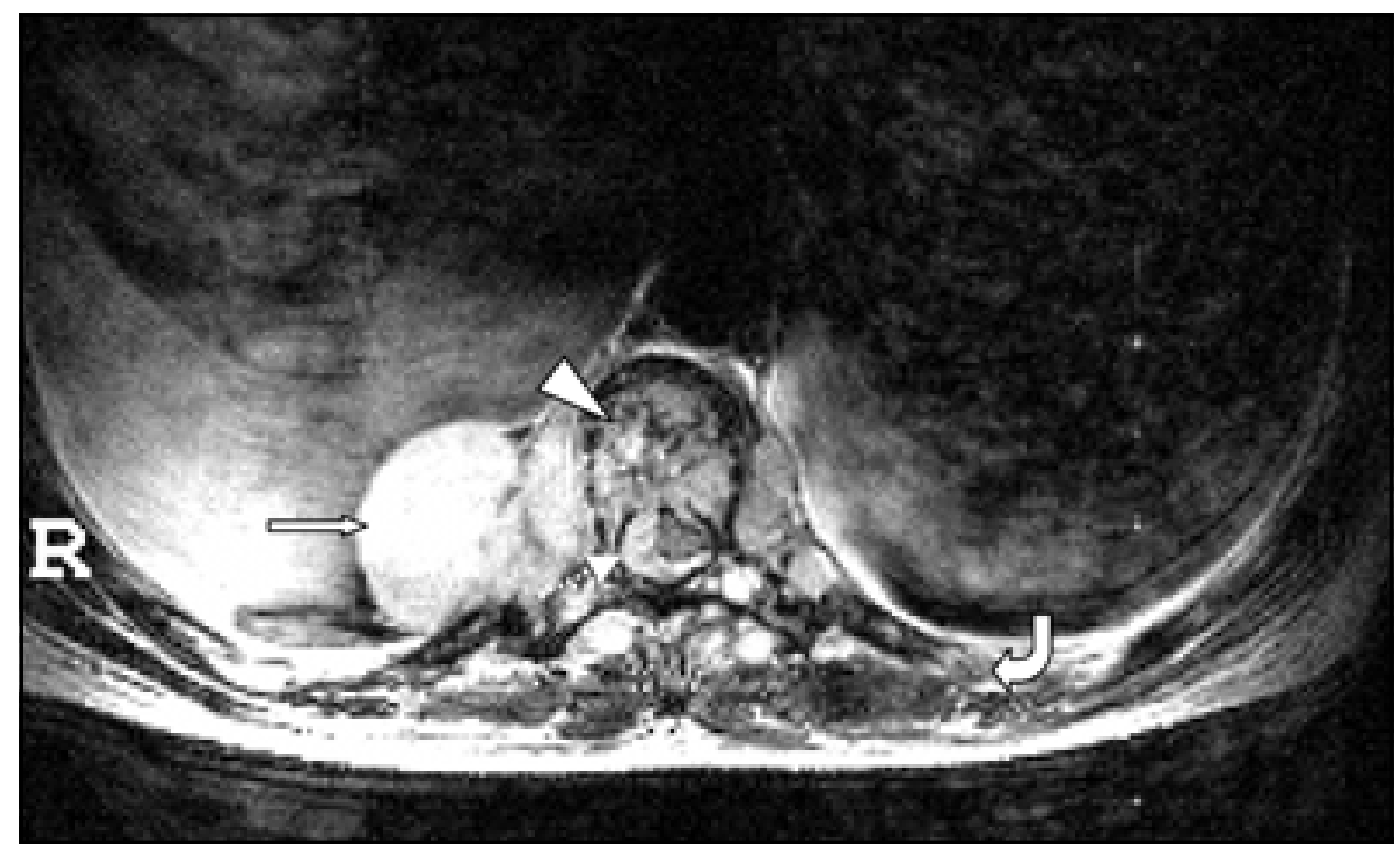

Fig 3. Axial T1-weighted image showing a large right pulmonary (thick arrow), vertebral body (arrow head), left rib (curved arrow), and intra-axial metastases (dotted-line arrow). $(R=$ right).

Surgery has been cited as a pathway for dissemination since the lumen of blood vessels is exposed and tumor cells may be carried to distant sites. Ventricle Peritoneal shunt (VP-shunt) is described as another pathway for dissemination of tumor cells. These observations are based on numerous publications reporting the greater incidence of metastases in patients who undergo surgery ${ }^{10,17}$ or VP-shunt ${ }^{9}$. However, several reports considered the dissemination through surgery or VP-shunt questionable, since regardless of whether the surgical procedure was performed, the location of extraneural metastases, incidence and the time of appearance of systemic disease are the same. This suggests that both the surgery and insertion of VP-shunt do not increase the likelihood of an unfavorable prognosis due to systemic metastases ${ }^{7}$. Complete tumor resection decreases the frequency of local recurrence, however a relationship between the extent of surgical resection and extraneural metastases has not been found ${ }^{5,7}$.

The gene expression of the PF - PNET that metastasizes is probably different from the gene expression of the PF - PNET that is restricted to the cerebellum. This is a possible explanation of the presence of systemic metastases in some patients, irrespective of the treatment applied, age of the patient, extent of tumor resection, sex and the presence of VP shunt? Platelet - derived growth factor receptor alpha (PDGFRA) and members of the downstream RAS / mitogen - activated protein kinase (MAPK) signal transduction pathway are up regulated in metastatic PF - PNET, and may act as therapeutic target along with HAS proteins and PDGFRA inhibitors ${ }^{18}$. The presence of the iso (17q) chromosome has also been reported as prognostic factor ${ }^{19}$.

The treatment of the PF - PNET requires surgical resection as complete as possible and the rational use of radiation and chemotherapeutic drugs as an adjuvant therapy. There are many regimens for radiation therapy ( XRT ). Posterior fossa doses are defined around $55 \mathrm{~Gy}$ and craniospinal axis doses around $30 \mathrm{~Gy}$ (20) and $35 \mathrm{~Gy}^{21-23}$. Radiation therapy is recommended for all patients after surgical procedure as prophylactic treatment to prevent local and distant CNS recurrence.

The benefits of chemotherapy are yet to be straightforwardly defined, as compared to radiation therapy. Studies addressed to evaluate chemotherapy have used different classifications for low and high risk patients and the groups of patients have not been uniform. However, there is a tendency towards the use of a combination of Vincristine, CCNU, prednisone, procarbazine and methotrexate ${ }^{16,21,22,24}$ for rescue therapy or for high risk patients. This includes those with distant metastases, bone marrow tumoral cells, spinal seeding and VP shunt. Unfortunately, intensive chemotherapeutic regimens fail to show positive effects and eventually replace or diminish $\mathrm{XRT}^{16,21,22}$ in order to lower its side effects especially in children. 
The chance of cure for PF - PNET has improved in the last decades ${ }^{16,25}$. A five year survival has increased from previous reports of approximately $50 \%{ }^{5}$ to recent reports showing a higher range (50 to $80 \%$ ) for a bigger time span (ten years) ${ }^{16,23}$. The reasons for the increase in survival rates are due to more complete surgical resection achieved with microoperative techniques, along with the rational use of chemotherapy and radiation therapy.

Systemic metastases constitute a rare complication of PF - PNET, that changes the outcome and are an obstacle to long term survival. Prevention to local and CNS recurrence is possible and usually performed. The presence of distant metastases, however, is difficult to avoid with our current therapy ${ }^{8,16}$. Further studies on molecular biology and the gene expression of the PF - PNET may shed light on the biological properties of the tumors that metastasize and the comprehension of the pathophysiology may guide new forms of treatment.

\section{REFERENCES}

1. Bailey $\mathrm{P}$, Cushing H. Medulloblastoma cerebelli: a common type of midcerebelar glioma of childhood. Arch Neurol Psych 1925;14:192-224.

2. Hart MN, Earle KM. Primitive neuroectodermal tumors of the brain in children. Cancer 1973;32:890-897.

3. Rorke LB. The cerebellar medulloblastoma and its relationship to primitive neuroectodermal tumors. J Neuropathol Exp Neurol 1983;42:1-15.

4. Nelson AA. Metastases of intracranial tumor. Am J Cancer 1936;28:1-12.

5. DiRocco C, Iannelli A, Tancredi A. Patterns of failure in surgical therapy of medulloblastomas. J Neurosurg Sci 1995;39:1-6.

6. Farwell JR, Flannery JT. Adult ocurrence of medulloblastoma. Acta Neurochir 1987;86:1-5.

7. Berger MS, Baumeister B, Geyer, JR, Milstein J, Knev PM, LeRoux PD. The risks of metastases from shunting in children with primary central nervous system tumors. J Neurosurg 1991;74:872-877.
8. Chamberlain MC, Silver P, Edwards MS, Levin VA. Treatment of extraneural metastatic medulloblastoma with a combination of cyclophosphamide, adriamycin and vincristine. Neurosurgery 1988;23:476-479.

9. Rochkind S, Blatt I, Sadeh M, Goldhammer Y. Extracranial metastases of medulloblastoma in adults: literature review. J Neurol Neurosurg Psychiatry 1991;54:80-86.

10. Sheikh B, Kanaan I. Lymph node metastasis in medulloblastoma. Pediatr Neurosurg 1994;20:269-271.

11. Akyus C, Yalcin B, Kutluk T, Cila A, Buyukpamukcu M. Brief report : medulloblastoma with widespread skeletal metastases presenting with hypercalcemia. Med Pediatr Oncol 1999;33:126-128.

12. Algra PR, Postma T, Van Groeningen CJ, Van Der Valk P, Bloem JL, Valk J. MR imaging of skeletal metastases from medulloblastoma. Skeletal Radiol 1992;21:425-430.

13. Olson EM, Tien RD, Chamberlain MC. Osseous metastasis in medulloblastoma: MRI findings in an unusual case. Clin Imaging 1991; 15:286-289.

14. Vieco PT, Azouz EM, Hoeffel JC. Metastases to bone in medulloblastoma. Skeletal Radiol 1989;18:445-449.

15. Lamovec J, Pogaenik A. Metastatic medulloblastoma to the breast. Virchows Arch 2001;439:201-205.

16. Krouwer HG, Vollmerhausen J, White J, Prados MD. Desmoplastic medulloblastoma metastatic to the pancreas : case report. Neurosurgery 1991;29:612-616.

17. Morild I, Mork S, Nyland H. Metastasizing neuroectodermal tumour. J Neurol 1982;227:151-155.

18. MacDonald TJ, Brown KM, LaFleur B, et al. Expression profiling of medulloblastoma: PDGFRA and the RAS / MAPK pathway as therapeutic targets for metastatic disease. Nat Genet 2001;29:143-152.

19. Stuart AG, Pearson AD, Emslie J, et al. Cytogenetic abnormalities in a disseminated medulloblastoma. Med Pediatr Oncol 1993;21:295-298.

20. Bouffet E, GentetJC, DozF, etal. Metastatic medulloblastoma: the experience of the french cooperative M7 group. Eur J Cancer 1994;30: 1478-1483.

21. Zeltzer PM. Metastasis stage, adjuvant treatment and residual tumor are prognostic factors for medulloblastoma in children: conclusions from the children's cancer group 921 randomized phase III study. J Clin Oncol 1999;17:832-845.

22. Bailey CC, Gnekow A, Wellek S, et al. Prospective randomized trial of chemotherapy given before radiotherapy in childhood medulloblastoma. International Society of Paediatric Oncology (SIO) and the German Society of Paediatric Oncology (GPO): SIOP II. Med Pediatr Oncol 1995;25:166-178.

23. Berry M, Jenkin R, Keen C, Nair B, Simpson W. Radiation treatment for medulloblastoma. J Neurosurg 1981;55:43-51.

24. Neidhartdt MK, Bailey CC. Prospective randomized cooperative medulloblastoma trial (MED 84) of the International Society of Paediatric Oncology (SIOP) and the German Society of Paediatric Oncology (GPO). Childs Nerv Syst 1987;3:70-73.

25. Sure U, Berghorn WJ, Bertalanffy $\mathrm{H}$, et al. Staging, scoring and grading of medulloblastoma: a postoperative prognosis predicting system based on the cases of a single institute. Acta Neurochir 1995;132:59-65. 